\title{
Aile Planlaması ve Kontraseptif Metotlar
}

\author{
Family Planning and Contraceptive Methods
}

\author{
Sabriye Gamze Seyrek ${ }^{1}$ \\ 1 Intern Doktor, Gazi Üniversitesi Tıp Fakültesi, Ankara, Türkiye, s.gamzeseyrek@gmail.com
2 İntern Doktor, Gazi Üniversitesi Tıp Fakültesi, Ankara, Türkiye, mahmutckrgl@gmail.com
${ }^{3}$ Intern Doktor, Gazi Üniversitesi Tıp Fakültesi, Ankara, Türkiye, nazlincekara19@icloud.com
}

Muhammet Mahmut Çakıroğlu²

Nazlı Incekara ${ }^{3}$

Öz

Aile planlaması; bir çiftin bakabilecekleri sayıda ve istedikleri zaman çocuk sahibi olmalarıdır. Aile planlaması; tüm gebeliklerin yaklaşık \% 50'sini oluşturan istenmeyen gebeliklerin önlenmesinde ve istenmeyen gebeliklere bağı olarak artan gebelik kaybı (abortus ), küretaj ve anne ölüm oranının azaltılmasında, cinsel yolla bulaşan hastalıkların azaltıması, toplumun sosyoekonomik düzeyinin yükseltilmesi gibi çeşitli anne, bebek ve toplum sağlığı konularında önemli bir yer tutmaktadır. İstenmeyen gebeliklerin yaklaşık yarısı kontraseptif yöntemler yanlış ya da eksik kullanıldığı, kalan yarısı da hiç kontraseptif yöntem kullanımadığı için meydana gelmektedir; dolayısıyla aile planlamasının daha doğru ve etkili bir biçimde yapılabilmesi için kontraseptif metotların çeşitleri, işleyiş mekanizmaları ve etkililikleri ve toplumda kullanıma oranları iyi bilinmelidir. Kontraseptiflerin doğru kullanımları ve çeşitleri, etkililikleri üzerinde önemli bir role sahiptir; örneğin yapılan bazı çalışmalarda rahim içi araçlar ve deri altı implantlar gibi uzun etkili yöntemlerin istenmeyen gebelikleri önlemede daha etkili olduğu görülmüştür. Kontraseptiflerin doğru seçimi, doğru kullanımı ve kontraseptif yöntemlerin daha iyi bilinmesiyle daha etkili bir aile ve nüfus planlaması yapılabilir.

Anahtar Kelimeler: Kontraseptif Metotların Çeşitleri, Kontraseptif Etkililikleri, Aile Planlaması ve Yararları.

\begin{abstract}
Family planning is that a couple have as many children as they can care for and whenever they want. Family planning plays an important role in preventing unintended pregnancies that make up about $\% 50$ percent of all pregnancies and decreasing abortion, curretage, maternal mortality rate, sexual transmitted diseases because of unintented pregnancy and improvement various subjects about mother, baby and public health like raising the socioeconomic level of society. $\% 50$ percent of unintented pregnancies occur because of incomplete and incorrect using of contraceptive methods and no contraceptive method is used in the remaining \% 50 percent of unintented pregnancies. So types of contraceptive methods, funtional mechanism and effectiveness of contraceptives and usage rate of contraceptives in community should be known well for effective family planning. Correct usage of contraceptive methods and types of contraceptives have significant role on effectiveness of the methods and these effects have been seen in different studies. For example some studies show that long acting reversible contraceprives like intrauterin devices and subdermal implants are more effective in preventing unintented pregnancies. With the right choice and the correct using of contraceptives and the more knowledge about contraceptive methhods, better family and population planning can be done.
\end{abstract}

Keywords: Types of Contraception Methods, Effectiveness of Contraception, Family Planing and it's Benefits. 


\section{GiRiş}

Aile planlaması; ailelerin bakabilecekleri sayıda istedikleri zaman çocuk sahibi olmalarıdır. ( toker, 2006 ) Aile planlamasında önemli bir yeri olan kontrasepsiyon ise çeşitli parçaların, cinsel uygulamaların, kimyasalların, ilaç ve ya cerrahi uygulamaların kullanılarak kasıtlı olarak gebeliğin önlenmesidir. ( Rakhi ve Sumathi, 2011)

Aile planlaması istenmeyen gebelikleri önlemede önemli bir role sahiptir. Dünyada 2015 ve 2019 yılları arasında gerçekleşen gebeliklerin yaklaşık olarak yarısı istenmeyen gebeliktir. Bu istenmeyen gebeliklere bağlı olarak ise yılda yaklaşık olarak yirmi beş milyon anne ve çocuk sağlığı açısından güvenliği düşük olan gebelik kaybı ( abortus ) ve 47.000 anne ölümü gerçekleşiyor. ( Dünya Sağlık Örgütü, 2019 )

2013 yılı Türkiye Nüfus ve Sağlığı verilerine göre; gerçekleşen bütün doğumların \% 13'ünün istenmediği, tüm gebelikler içinde \%11'inin plansız olduğu, düşük oranının ise tüm kadınlar içerisinde \% 23 oranında en az bir kez kendiliğinden, \% 14'ünün ise en az bir kez isteyerek olduğu tespit edilmiştir. Tüm bu oranlara rağmen Türkiye'de herhangi bir modern kontrasepsiyon yöntemi kullanan kadın oranı \% 42.5'tir. (Şenoğlu, Çoban ve Karaçam, 2019 ) 2018 Türkiye Nüfus ve Sağlığı araştırmalarına göre de benzer bir oran söz konusudur. Gerçekleşen bütün doğumların \% 15'inin istenmediği, \%11'inin ise gelecekte olmasının istendiği tespit edilmiştir; düşük oranının ise tüm kadınlar içerisinde \% 22 oranında en az bir kez kendiliğinden, \%6'sının ise en az bir kez isteyerek olduğu belirlenmiştir. Tüm bu oranlara rağmen Türkiye'de modern kontraseptif yöntem kullanan kadın oranı \% 49'dur.(Hacettepe Üniversitesi Nüfus Etütleri Entitüsü, 2019)

İstenmeyen gebeliklerin önlenmesi ve aile planlamasının etkin bir biçimde yapılabilmesi artan düşük oranını ve anne ölüm oranını (maternal mortalite ) azaltmak, cinsel yolla bulaşan hastalıkları azaltmak ve toplum sağlığını iyileştirme açısından önemlidir. Doğru kontraseptif yöntemin seçilmesi ve bu yöntemlerin daha koruyucu olabilmesi için kontraseptif yöntemlerin kullanım oranları, mekanizmaları, etkililikleri ve etkililikleri üzerinde rol oynayan faktörler bilinmelidir. ( Shaw, 2010)

\section{KONTRASEPTIF METODLAR VE KULLANIMI}

Kontraseptif yöntemler öncelikle geleneksel ve modern yöntemler olarak ikiye ayrılır. Doğal yöntemlerin içinde cinsel kaçınma, geri çekilme yöntemi, vajinal duş ve emzirme gibi yöntemler yer alır.
Modern yöntemler işlevini fertilizasyonu önleyerek ve ya döngünün hormonal aşamalarına müdahale ederek işlevini gerçekleştirir ve dolayısıyla bariyer yöntemler ve bariyer olmayan( nonbariyer) yöntemler olarak ayrilır. Bariyer yöntemler erkek ve kadın kondomu, diyafram, servikal başlık ,spermisit yöntemleridir. Bariyer olmayan yöntemlerden geri dönüşümlü olanlar rahim içi araç, hormanal kontraseptifler ( oral kontraseptifler, enjekte edilebilen kontraseptifler, deri altı implantları ,transdermal yamalar ve transvajinal halka ); geri dönüşümsüz yöntemler ise tüp ligasyonu ve vazektomidir. Bunlara ek olarak bir de ilişki sonrası ( postkoital) acil kontraseptif yöntem vardır. Sağlık bakanlığının 2018 verilerine göre halen evli kadınlar içinde herhangi bir aile planlaması yöntemi kullanan kadınların oranı 2013'te \% 74 iken 2018 'de \% 70 olarak tespit edilmiştir. Bunların içerisinde modern yöntemleri kullanan kadınları oranı yaklaşık \% 49 , geleneksel yöntemleri kullananları oranı \% 20, hiçbir kontraseptif yöntem kullanmayan kadınların oranı ise \% 30'dur.( Hacettepe Üniversitesi Nüfus Etütleri Enstitüsü, 2019)

\subsection{Cinsel Kaçınma}

Gebelik riskinin arttığı ovulatuar dönemde ilişkiden kaçınmaktır. Bazal vücut ısısı ölçümü, takvim yöntemi, servikal mukus yöntemi ve bu yöntemlerin kombinasyonu ovulasyon gününü takip etmede kullanılır. Takvim yönteminin sağlık bakanlığını en son verilerine göre Türkiyede kullanılma oranı \%1.1 dir. (Hacettepe Üniversitesi Nüfus Etütleri Enstitüsü, 2019) ) Bu yöntem doğru kullanıldığında 1 yılda gebelik oranı \%1-9, doğru kullanılmadığında ise \%20'dir. ( Colquitt ve Martin, 2017 )

\subsection{Geri Çekilme Yöntemi}

Penisin ejekülasyondan önce vajenden ve bulaş riskini önlemek için dış genital organlardan geri çekilmesidir. Bu yöntem Türkiye'de 2013 verilerine göre kadınların \%26.4, 2018 verilerine göre ise \% 20'si tarafından kullanılmaktadır. ( Ana Çocuk Sağlığı ve Aile Planlaması Genel Müdürlüğü, 2009; Hacettepe Üniversitesi Nüfus Etütleri Enstitüsü, 2019) Bu yöntem doğru kullanıldığında bir yılda gebelik oranı \%4 iken yanlış kullanımda \%19 olarak hesaplanmış. ( Colquitt ve Martin, 2017 )

\subsection{Erkek Kondomu}

Doğum kontrolünde kullanılan en yaygın ve para ile ulaşımı kolay olan modern yöntemdir. Kondomlar lateksten ve günümüzde artık lateks dışı poliizopren benzeri maddelerden yapılır. Hem kontrasepsiyon amaçlı hem de cinsel geçişli hastalıklardan korunma maksadı ile kullanılır. (Walsh vd., 2003) Türkiye'de kullanım oranı \% 19'dur.Beş 
yıl öncesine göre kullanım oranı \%3 artmıştır.( Hacettepe Üniversitesi Nüfus Etütleri Enstitüsü,2019 ) Bu yöntemi kullanan çiftlerde gebelik oranı doğru kullanıldığında \%3 iken yanlı ş kullanıldığında \%14'tür.( Ana Çocuk Sağlığı ve Aile Planlaması Genel Müdürlüğü, 2009)

\subsection{Kadın Kondomu}

Sentetik lateksten yapllır ve vajinaya kabaca oturtulur. 2 tane halka içerir ve halkalardan birisi vajen içinde diğeri ise dışında kalacak şekilde tasarlanmıştır. Cinsel birleşmeden en az 8 saat önce takılmalıdır. (Trussell, Strickler ve Vaughan, 1993)Bu yöntem başarılı kullanıldığında bir yılda gebelik oranı \%5 iken yanlık kullanıldığında \%21'dir. ( Ana Çocuk Sağlığı ve Aile Planlaması Genel Müdürlüğü, 2009)

\subsection{Diyafram}

Lateks ve ya silikondan yapılan vajen duvarına yerleşen ve serviksi tamamen kaplayan bir yöntemdir .Genellikle spermisit ile beraber kullanılır ve böylece fiziksel ve kimyasal bariyer oluştururlar. Erkek kondomu ile kullanilınca etkililik artırılabilir. Diyafram cinsel birleşmeden sonra en az 6 saat çıkarılmamalı, en fazla ise 24 saat tutulmalıdır. Dezavantajlarından birisi idrar yolu enfeksiyonu sıkıı̆ını artırmasıdır. (Secor, 1992) Spermisit ile beraber kullanılınca 1 yılda gebelik oranı doğru kullanımda \% 6, yanılıs kullanımda \% 20'dir. ( Ana Çocuk Sağlığı ve Aile Planlaması Genel Müdürlüğü, 2009 )

\subsection{Spermisit}

Kimyasal bir bariyer oluşturarak etkisini gösterir ve spermlerin ölümüne yol açar. Etkinlğinde kullanıma başlanma amanı önemlidir ve sperme etki edebilmesi için vajinada 10 ile 15 dakikaya intiyacı vardır. Spermisitler; krem, köpük, jel, vajinal film ve sünger formlarda bulunurlar.( Colquitt ve Martin, 2017)

\subsection{Servikal Başlık}

Kubbe şeklindedir ve serviksi tamamen kaplayarak vajinal duvarlara tutunur. Cinsel birleşmeden 42 saat önce takılmalı ve 6 saat sonrasına kadar çıkarımamalıdır. Genellikle spermisit ile beraber kullanilır. (Richardson, 2002 ) Doğum yapmış kadınlarda 1 yıl içinde doğru kullanımda $\%$ 26, yanlış kullanımda \% 40 gebelik intimali vardır .Doğum yapmamış kadınlarda ise doğru kullanıldığında $\%$ 9, yanlış kullanımda \% 20 gebelik intimali vardır. ( Ana Çocuk Sağlığı ve Aile Planlaması Genel Müdürlüğü, 2009)

\subsection{Rahim İçi Araçlar}

Hormon içeren ve içermeyen formu vardır. Hormon içeren formunda levonorgestrel salınımı yaparak siklusa müdahale eder. Hormon içeren bu formlardan birisi $52 \mathrm{mg}$ levonorgestrel içerir ve 5 yıl süre koruma sağlar, bir diğeri $13.5 \mathrm{mg}$ içerir ve 3 yıl koruma sağlar. Hormon içermeyen formu ise bakırlı rahim içi araçtır. Sperm transportuna etki ederek fertilizasyonu ve implantasyonu önlediği düşünülmektedir. Hormon içeren forma göre yan etkisi daha azdır. Türkiye'de kadınların \%14'ü rahim içi araç methodunu kullanmaktadır. 0Bir yılda gebe kalma oranı doğru kullanımda \%0.6, yanlış kullanımda \%0.8'dir.( Colquitt ve Martin, 2017 )

\subsection{Oral Kontraseptifler}

Oral kontraseptifler 2 grupta incelenir birinci grup hem östrojen hem progesteron içerirken diğer grup yalnızca progesteron içerir ve minipill olarak da adlandırılır, Kombine oral kontraseptifler 21 aktif , 7 inaktif tablet içerir. Östrojen dozu 20-50 mikrogram arası değişir, progesteron dozu ise kullanılan preparatın bileşenine göre değişir. Minipiller ise sadece progesteron içerir ve tüm tabletler aktiftir. Emzirme döneminde rahatıkla kullanılabilir. Oral kontraseptif yöntemler Amerika'da en sık kullanılan yöntemdir fakat Türkiye kullanım oranı \% 5'tir. Yıllık gebe kalma intimali kombine oral kontraseptfilerde doğru kullanımda \%0.1 iken yanlış kullanıldığında $\% 6$ 'dır. Minipillde ise yıllık gebe kalma intimali doğru kullanımda \%0.5 iken yanlış kullanımda \%1'dir.(Colquitt ve Martin, 2017)

\subsection{Enjekte Edilebilen Kontraseptifler}

$150 \mathrm{mg}$ medroksiprogesteron asetat içeren te doz şeklinde şırıngalardır. 3 ayda bir bu konuda eğitimli bir sağlık çalışanı tarafından uygulanır. Bu yöntemle fertilizasyona geri dönme kullanımı bırakıldıktan sonra 1824 ay sürebilir. 1 yılda gebe kalma oranı $\% 0.3$ 'tür. Ancak Türkiye'de kullanımı \%1.1 den daha düşüktür.(Trussell ve Guthrie, 2007: 19 ; Ana Çocuk Sağlığı ve Aile Planlaması Genel Müdürlüğü, 2009 )

\subsection{Subdermal İmplant}

$216 \mathrm{mg}$ levonorgestrel içeren, etkinliği 7 yıl olan ve 68 mg etonorgestrel içeren ve etkinliği 3 yıl olan uzun süreli kontraseptif yöntemdir. Çubuk lokal anestezi uygulanarak invaziv olarak yerleştirilir, işlem yaklaşık 5 dakika sürer ve duş almak, denize girmek gibi durumlarda bu bölge etkilenmez. Implant çıkarıldıktan 3-4 hafta sonra ovulasyon tekrar başlar. Laktasyon sırasında kullanımı güvenlidir. Türkiye'de kullanım oranı \%1'den daha azdır. 1 yilda gebe kalma intimali \% 1'Den daha azdır. (Meckstroth ve Darney, 2001)

\subsection{Diğer Kontraseptif Yöntemler}

Transdermal yama; günlük 150 mikrogram norelgestramin 
ve 35 mikrogram etinil estradiolü transdermal yolla vücuda dağıtır. Menstrual siklusu takiben 3 hafta boyunca haftada 1 tane uygulanır ve 1 hafta boş bırakılır. Türkiye'de kullanım oranı \%1'den azdır.

Transvajinal halka; vajinaya yerleştirilir ve 3 hafta orada kalır, bir hafta ara verilir. Günlük 15 mikragram etinil estradiol ve 120 mikrogram etonorgestrel salınımı yapar. Kullanım oranı Türkiye'de \%1'den daha azdır.

Tüp ligasyonu; kalıcı sterilizasyon isteyen çiftlerde uygulanır.1 yılda gebe kalma oranı \% 0.5'tir.Türkiye'de kullanım oranı \% 10'dur. 30-34 yaş arası kadınlarda bu yöntemin daha çok tercih edildiği görülmüştür.

Vazektomi; erkek üreme organı vas deferensin bir kısmı eksize edilerek ejekülasyonda sperm pasajı engellenir. Bu yöntemle kalıcı sterilizasyon sağlanır. Türkiye'de kullanım oranı \%1'den daha azdır. 1 yılda gebe kalma oranı \% 0.1 'dir. 0

\subsection{Postkoital Kontrasepsiyon}

0.75 gram levonorgestrel içeren ve 2 tablet olan formu ve $1.5 \mathrm{mg}$ levonorgestrel içeren ve 1 tablet içeren formu vardır. Tek tablet olan ilaç cinsel birleşmeden en geç 72 saat sonra alınmalıdır. 2 tablet içeren formda ilk doz 72 saat içinde alınmalı, 2. doz ise onu takip eden 12. saatte alınmalıdır. Bu yöntem ile Amerika'da istenmeyen gebeliklerde \%75 azalma sağlanmıştır. Medikal takibe intiyaç duyulmadığından, toksisite riski çok az olduğundan ve kişi kendi kararıyla kolayca erişebileceğinden etkili bir yöntemdir.( Colquitt ve Martin, 2017 )

Tablo 1. Aile Planlaması Yöntentemlerinin Etkililiği (Gebeliği Önlemedeki Önlemedeki Başarısızlık Oranı)

\begin{tabular}{|c|c|c|c|}
\hline \multirow[b]{2}{*}{ Etkililik } & \multirow[b]{2}{*}{ Aile Planlaması Yöntemi } & \multicolumn{2}{|c|}{ İlk 12 aylık kullanımda 100 kadın başına gebelik } \\
\hline & & $\begin{array}{l}\text { Kullanıma uygun } \\
\text { kullanılmadığında }\end{array}$ & $\begin{array}{l}\text { Doğru ve düzenli } \\
\text { kullanıldığında }\end{array}$ \\
\hline \multirow[t]{7}{*}{ Her zaman çok etkilidir } & Norplant & 0.1 & 0.1 \\
\hline & Vazektomi & 0.2 & 0.1 \\
\hline & Kombine Enjektabl & 0.3 & 0.3 \\
\hline & Depo Provera ve NET-En & 0.3 & 0.3 \\
\hline & Tüp Ligasyonu & 0.5 & 0.5 \\
\hline & TCu-380A RIA & 0.8 & 0.6 \\
\hline & $\begin{array}{l}\text { Yalnızca Progesteron İçeren } \\
\text { haplar }\end{array}$ & 1 & 0.5 \\
\hline \multirow{2}{*}{$\begin{array}{l}\text { Kullanıma uygun } \\
\text { kullanılmadığında } \\
\text { etkilidir. Doğru ve sürekli } \\
\text { kullanıldığında çok etkilidir. }\end{array}$} & Laktasyonel amenore & 2 & 0.5 \\
\hline & Kombine Oral Kontraseptif & $6-8$ & 0.1 \\
\hline \multirow{4}{*}{$\begin{array}{l}\text { Kullanıma uygun } \\
\text { kullanılmadığında az etkilidir. }\end{array}$} & Erkek Kondomu & 14 & 3 \\
\hline & Geri Çekme & 19 & 4 \\
\hline & Spermisitle Birlikte Diyafram & 20 & 6 \\
\hline & Takvim vb. Yöntemler & 20 & $1-9$ \\
\hline \multirow{6}{*}{$\begin{array}{l}\text { Yalnızca doğru ve sürekli } \\
\text { kullanıldığında }\end{array}$} & Kadın Kondomu & 21 & 5 \\
\hline & Spermisit & 26 & 6 \\
\hline & Servikal Başlık & & \\
\hline & Doğum yapmamış kadınlarda & 20 & 9 \\
\hline & Doğum yapmış kadınlarda & 40 & 26 \\
\hline & Yöntem Kullanmama & 85 & 85 \\
\hline
\end{tabular}




\section{KONTRASEPTIF METOTLARIN ETKILILIKLERI}

Dünya genelinde gebeliklerin \% 50'si istenmeyen gebelik olarak belirtilmiştir. İstenmeyen gebeliklerin \% 50'si de kontrasepsiyon yöntemlerinin yanlış ya da eksik kullanımı sonucudur. Geri kalan \% 50'de hiç kontrasepsiyon yöntemi kullanmamaktan kaynaklanmaktadır.

Kullanılan kontrasepsiyon yönteminin, kullanan yaş grubuna ve kullanma devamlılığına bağlı olarak etkili olma oranı değişmektedir.

Yapılan bir çalışmada farklı yaş gruplarında , farklı sosyal statüye sahip ve farklı eğitim düzeyine sahip yaklaşık 10 bin kadın seçilmiş, hepsine bir doğum kontrol yöntemi seçilmiş, ücretsiz olarak hizmet sağlanmış ve bu kadınlar 3 yıl (2007-2011) süre ile izlenmiş. ( Hubacher, Spector, Monteith, Chen ve Hart, 2016)

Bu çalışmaya göre rahim içi araçlar ve deri altı implantların en etkili yöntemler olduğu sonucuna varılmış. Ayrıca, DMPA(depo medroxyprogesterone acetate) kullananlar da etkililik açısından değerlendirildiğinde yaş gruplarına göre farklılık gözlenmemiş.

\section{Grafik 1. Kontraseptif Yöntemlerin Başarısızlık Oranları}

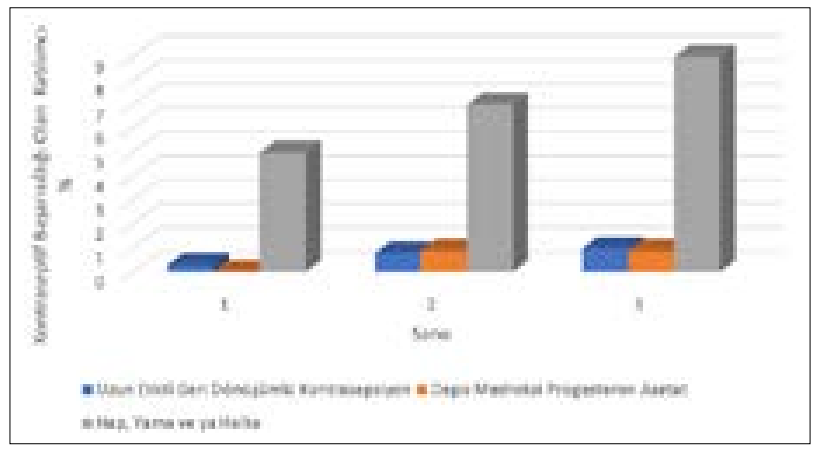

Oral kontraseptif, yama ve halka kullananların ise istenmeyen gebelik oranı çok daha fazla çıkmış. Bunların arasında da 21 yaş altı kadınların daha yaşlı kadınlara göre istenmeyen gebelik oranı daha fazla olmuş. Çünkü oral kontraseptifler günlük düzenli kullanım gerektiren yöntemlerdir ve 21 yaş altında 2-3 günde bir oral kontraseptif kullanıldığı, devamlılığın sağlanamadığı görülmüş. ( Hubacher vd, 2016 )

Uzun etkili kontraseptif yöntemlerin (rahim içi araç , subdermal implant ), kısa etkili yöntemlere ( kontraseptif ilaçlar ve enjekte edilebilen kontrasepsiyon ) göre daha etkili olduğu sonucuna varılmış. Ancak bunun yanında uzun etkili yöntemlerin ulaşılabilirliğinin daha az olduğu gösterilmiş.
916 kadını içeren ve randomize kısa etkili geri döndürülebilen kontrasepsiyon, uzun etkili etkili geri döndürülebilen kontrasepsiyon ve tercihen kısa etkili geri döndürülebilen kontrasepsiyon kullananlar olmak üzere 3 grup oluşturulan bir gözlemsel çalışmada 1 yılın sonunda uzun etkili kontraseptif yöntemlerin korumada çok daha etkili olduğu görülmüş.

Uzun etkili geri döndürülebilen kontraseptif yöntemlerin kullanımında istenmeyen gebelik oranının \%0-\%5 arasında değiştiği, kısa etkili geri döndürülebilen kontraseptif yöntemlerin kullanımında \%0,4-\%12 oranında değiştiği gözlemlenmiş. Kullanıcıların çalışma sonunda memnuniyet oranları yaklaşık aynı olarak \%90 bulunmuş. (Hubacher vd, 2016)

\section{AILE PLANLAMASININ FAYDALARI}

İstenmeyen gebeliklerin önlenmesi ve gebeliklerin planlı yapılması toplum sağlığı, ekonomik refah ,anne ve çocuk sağlığı gibi birçok konuyla yakandan ilgilidir. ( Dünya Sağlık Örgütü, 2020 ) Aile planlamasının temelde sağladığı faydalar şu şekilde anlatılabilir:

Genç erişkin yaşlar; doğum kontrol yöntemlerine ulaşım imkanlarının daha az olduğu zamanlardır ve bu yaşlarda aynı zamanda anne ölüm hızı oranı ve çocuk ölüm hızı oranı yüksektir. Bu zamanlarda planlı gebelik yapılması hem anne hem çocuk sağlığını iyileştirecek hem de hayatta kalma oranlarını arttıracaktır.(Bruce ve Bongaarts, 1995)un $><$ run para-style-id="EndNoteBibliography" $><$ char-props ascii-font="Times New Roman" ansi-font="Times New Roman" cs-font="Times New Roman"/><text preservespace="true" $>$ adresinden erişildi. $</$ text $></$ run $><$ / para $><$ para para-style-id="EndNoteBibliography" $><$ paraprops para-style-id="EndNoteBibliography" spaceafter="0" line-height="480" line-rule="ekauto" leftindent="720" first-indent="-720" $><$ char-pro

2018 Türkiye Nüfus ve Sağlık Araştırmaları'na göre 18 yaş altı ve 35 yaş üstü gebelikler, kısa doğum aralıkları (24 aydan küçük ), yüksek doğurganlık (4 ve üzerinde çocuk ) oranı bebek ölümleri için risk oluşturan etmenlerdendir. (Hacettepe Üniversitesi Nüfus Etütleri Enstitüsü, 2019)

İstenmeyen gebeliklerde tercih edilen yöntem küretajdır. $\mathrm{Bu}$ da çoğunlukla güvenli olmayan küretaj yöntemleridir. Bu durumküretajdan sonra anne ölüm oranını artırmaktadır. Aile planlaması ve doğum kontrol yöntemlerine ulaşım imkânlarının kolaylaştırılmasıyla güvenli olmayan kürtaj operasyonları azaltılıp anne sağlığı korunmuş olur. (Sah, 1991) 
Kadınlar çocuk yapma zamanını kontrol edemediği zaman eğitim öğrenimi aksayabilmekte, ekonomik gücünü eline alamadığı durumlar meydana gelebilmektedir. Bu durum hem kendi geçimini hem de çocuğunun geçimini kötü etkilemektedir. Kadının kendi hayatının kontrolünü eline almasında, hayatını planladığı şekilde devam ettirebilmesinde aile planlamasının büyük katkısı vardır.

Nüfus hızındaki artış sosyal ve ekonomik sorunları beraberinde getirmektedir. Ülkenin ekonomik gelişimini negatif etkilemektedir. İş bulma, barınma, gıda, okul, üniversite gibi sınırlı kaynaklarda rekabetçi bir ortam oluşturmaktadır. Aile planlamasıyla hem ailenin çocuklarına sunduğu refah düzeyi artırılabilir hem de çocukların gelecekteki refah ve huzura ulaşması kolaylaştırılabilir.

Aile planlamasıyla ayrıca cinsel yolla bulaşan hastalıkların yayılmasının önüne geçilebilir. Özellikle HIV/AiDS gibi hastalıkların erkeğe, kadına, çocuğa bulaş intimali azaltılabilir. Bu sayede insanların sağlığı korunmuş olur. Ayrıca tedavi için ayrılan maddi ödenekten, insan gücünden ve zamandan tasarruf edilerek aileler için daha iyi bir gelecek planlanabilir. (Ochieng, 2003)

\section{SONUÇ VE ÖNERILER}

Aile planlaması ve kontrasepsiyon yöntemlerin etkili kullanımı istenmeyen gebeliklerin önlenmesinde ve anne, çocuk ve toplum sağlının iyileştirilmesinde önemli bir yer tutar. Kontrasepsiyon yöntemlerinin etkililikleri ile ilgili çalışmalara bakıldığında bu yöntemlerin doğru uygulanmasının, kullanımda sürekliliğin ve yöntemin çeşidinin 1 yılda gebe kalma oranları üzerinde önemi olduğu görülmektedir.

Kontrasepsiyon yöntemlerin içerisinde modern yöntemlerin daha etkili olduğu; bu yöntemler içerisinde ise tüp ligasyonu ve vazektomi gibi geri dönüşümsüz yöntemlerin en etkili olduğu, geri dönüşümü olan yöntemler içinde ise rahim içi araç uygulamaları ve subdermal implant gibi uzun etkili yöntemlerin en etkili olduğu görülmüş. Dolayısıyla Türkiye'de bu yöntemlerin yaygınlığını ve ulaşılabilirliğinin artırmak için kadınlara bu yöntemlerin kullanımı ile ilgili bilgiler özellikle birinci basamak sağlık kuruluşlarında daha etkin bir biçimde anlatılmalıdır. Bu yöntemlerin tanıtımı sağlık bakanlığı destekli reklamlarla yapılabilir. KETEM merkezleri gibi küçük birimler mahallelerde ve ya alışveriş merkezlerinin yakınlarında kurulabilir ve kontraseptif yöntemlerin etkileri ve kullanım şekilleri görseller, videolar ve sunumlarla anlatılabilir.
Yine yapılan çalışmalarda görülmüş ki 21 yaş altı kadınlarda daha çok oral kontraseptiflerin tercih edildiği ve düzenli ve doğru kontraseptif kullanımının etkili bir şekilde yapılamadığı görülmüştür. Dolayısıyla bu yaş grubu kadınlara kontraseptiflerin düzenli kullanımı ile ilgili bilgilendirmeler yapılmalı ve uzun etkili kontraseptifler önerilmelidir. Adölesan çağdaki genç kadın ve erkeklere okul döneminde rehber öğretmenler tarafından bilgi verilebilir, broşürler dağıtılabilir. Böylece daha etkin aile planlaması sağlanabilir.

\section{KAYNAKLAR / REFERENCES}

- Şenoğlu, A., Çoban, A., Karaçam, Z. (2019). İstenmeyen Gebelikler ve İsteyerek Yapılan Düşüklerin Değerlendirilmesi. Arşiv kaynak tarama dergisi, 28(4), 300-305. doi:10.17827/aktd.474072

- Bruce, J. B. ve Bongaarts, J. (1995). The Causes of Unmet Need for Contraception and the Social Content of

- Services. Population Council. 11 Şubat 2016 tarihinde http://www. jstor.org/stable/2137932 adresinden erişildi.doi:10.2307/2137932

- Colquitt, C. W. ve Martin, T.S. (2017). Contraceptive Methods: A Review of Nonbarrier and Barrier Products. Journal of Pharmacy Practice, 30, 130- 135. doi:10.1177/0897190015585751

- Ana Çocuk Sağlığı ve Aile Planlaması Genel Müdürlüğü. (2009). Aile Planlaması Danışmanlığı (ISBN 975-590-136-1).Ankara, TC. Sağlık Bakanlığı.

- Hubacher, D., Spector, H., Monteith, C., Chen, P. L., Hart, C (2016). Long-acting reversible contraceptive acceptability and unintended pregnancy among women presenting for short-acting methods: a randomized patient preference trial. American journal of obstetrics and gynecology, 216(2), 101-109. doi: 10.1016/j. ajog.2016.08.033

- High rates of unintended pregnancies linked to gaps in family planning services: New WHO study. (2019). 12 Aralık 2020 tarihinde https://www.who.int/news/item/25-10-2019-high-ratesof-unintended pregnancies-linked-to-gaps-in-family-planningservices-new-who-study adresinden erişildi.

- Rakhi, J. ve Sumathi, M. (2011). Contraceptive Methods: Needs, Options and Utilization. Obstetrics and Gynecology of Indi, 61(6), 626-634. doi: 10.1007/s13224-011-0107-7

- New estimates show worldwide fall in unintended pregnancies since 1990-1994. (2020). 15 Aralık 2020 tarihinde https://www. who.int/news/item/25-10-2019-high-rates-of-unintendedpregnancies-linked-to-gaps-in family-planning-services-newwho-study adresinden erişildi.

- Ochieng, B. M. N. (2003). Adolescent health promotion: The value of being a peer leader in a health education/ promotion peer education programme. Health education journal,62(1), 61-72. doi:10.1177/001789690306200107

- Sah, R. K. (1991). The Effects of Child Mortality Changes on Fertility Choice and Parental Welfare. The University Of Chicago Press Journall, 99, 582-606.

- Shaw, D. (2010).The ABC's of familY planning.. 10 Aralık 2020 tarihinde https://www. who.int/pmnch/media/news/2010/20100322_d_shaw_oped/en/ adresinden erişildi. 
- Toker, S. O. (2006). Aile Planlaması ve Acil Kontrasepsiyon. Nobel Medicus, 2(2), 4-9.

- Hacettepe Üniversitesi Nüfus Etütleri Enstitüsü. 2019. 2018 Türkiye Nüfus ve Sağlık Araştırması. ( ISBN 978-975-491-4931) .Hacettepe Nüfus Etürleri Enstitüsü, T.C. Cumhurbaşkanlığı Stateji ve Bütçe Başkanlığı ve TÜBiTAK, Ankara, Türkiye.

- Trussell, J. ve Guthrie , K. (2007). Choosing a contraceptive: efficacy, safety, and personal considerations. Hatcher , R., Trussell, J., Nelson, A. vd. (19. baskı ), Contraceptive Tecnology içinde (19-47. ss. ). New York, NY: Ardent Media

- Meckstroth, KR., Darney, PD. (2001). Implant Contraception. Semin Reprod Med.19(2), 339-354.w

- Walsh, TL., Frezieres, RG., Peacock, K., Nelson, AL., Clark, VA., Bernstein, L. (2003). Evaluation of the efficacy of a nonlatex condom: results from a randomized, controlled clinical trial. Perspect Sex Reprod Health. 35(2), 79-86.

- Trussel, J., Strickler, J., Vaughan, B. (1993). Contraceptive efficacy of the diaphragm, the sponge and the cervical cap. Fam Plann Perspect. 25(3), 100-105.

- Secor, R. (1992). The cervicel cap. NAACOG's Clinn Issuess. 3(2), 236-245.

- Richardson, B. (2002). Nonoxynol-9 as a vaginal microbicide for prevention of sexually transmitted infections: it's time to move on. JAMA. 287(9), 1171-1172. 